\title{
Young to Middle-Aged Dogs with High Amyloid- $\beta$ Levels in Cerebrospinal Fluid are Impaired on Learning in Standard Cognition tests
}

\author{
Herman Borghys $^{\mathrm{a}, *}$, Bianca Van Broeck ${ }^{\mathrm{a}}$, Deborah Dhuyvetter ${ }^{\mathrm{a}}$, Tom Jacobs ${ }^{\mathrm{a}}$, Katja de Waepenaert ${ }^{\mathrm{a}}$, \\ Tim Erkens ${ }^{\mathrm{a}}$, Melissa Brooks ${ }^{\mathrm{b}}$, Sandy Thevarkunnel ${ }^{\mathrm{c}}$ and Joseph A. Araujo ${ }^{\mathrm{c}}$ \\ a Janssen Research \& Development, a division of Janssen Pharmaceutica N.V., Beerse, Belgium \\ ${ }^{\mathrm{b}}$ Vivocore Inc, Toronto, Canada \\ ${ }^{\mathrm{c}}$ InterVivo Solutions Inc., Toronto, Canada
}

Handling Associate Editor: Elizabeth Head

\begin{abstract}
Understanding differences in Alzheimer's disease biomarkers before the pathology becomes evident can contribute to an improved understanding of disease pathogenesis and treatment. A decrease in amyloid- $\beta(A \beta)_{42}$ in cerebrospinal fluid (CSF) is suggested to be a biomarker for $A \beta$ deposition in brain. However, the relevance of CSF $A \beta$ levels prior to deposition is not entirely known. Dogs are similar to man with respect to amyloid- $\beta$ protein precursor (A $\beta P P$ )-processing, age-related amyloid plaque deposition, and cognitive dysfunction. In the current study, we evaluated the relation between CSF A $\beta_{42}$ levels and cognitive performance in young to middle-aged dogs (1.5-7 years old). Additionally, CSF sA $\beta P P \alpha$ and sA $\beta P P \beta$ were measured to evaluate $\mathrm{A} \beta \mathrm{PP}$ processing, and CSF cytokines were measured to determine the immune status of the brain. We identified two groups of dogs showing consistently low or high CSF A $\beta_{42}$ levels. Based on prior studies, it was assumed that at this age no cerebral amyloid plaques were likely to be present. The cognitive performance was evaluated in standard cognition tests. Low or high $\mathrm{A} \beta$ concentrations coincided with low or high $\mathrm{SA} \beta \mathrm{PP} \alpha$, sA $\beta \mathrm{PP} \beta$, and CXCL-1 levels, respectively. Dogs with high $A \beta$ concentrations showed significant learning impairments on delayed non-match to position (DNMP), object discrimination, and reversal learning compared to dogs with low $\mathrm{A} \beta$ concentrations. Our data support the hypothesis that high levels of CSF A $\beta$ in dogs coincide with lower cognitive performance prior to amyloid deposition. Further experiments are needed to investigate this link, as well as the relevance with respect to Alzheimer's disease pathology progression.
\end{abstract}

Keywords: Alzheimer's disease, amyloid- $\beta$ peptides, biomarker, cognition, dog

\section{INTRODUCTION}

Alzheimer's disease (AD) is the most common type of dementia and is characterized clinically by a progressive cognitive decline, which results in an inability to carry out daily activities and ultimately

\footnotetext{
${ }^{*}$ Correspondence to: Herman Borghys, Preclinical Development and Safety, Janssen Research \& Development, Turnhoutseweg 30, 2340 Beerse, Belgium. Tel.: +32 0146023 79; E-mail: hborghys@its.jnj.com.
}

death. Amyloid- $\beta(A \beta)$ plaques in the brain are one of the neuropathological hallmarks of Alzheimer's disease [1]. The "amyloid cascade hypothesis" proposes that cerebral amyloidosis is likely an early and initiating event of $\mathrm{AD}$ pathogenesis. Plaques are composed mainly of $A \beta_{x-42}$ peptides, which have the tendency to form aggregates and to precipitate [2,3]. Moreover, the disease process, as evidenced by an increased amyloid deposition in the brain and lowering of $A \beta_{42}$ in cerebrospinal fluid (CSF), begins years before clear 
dementia symptoms appear [4]. Therefore, it is generally recognized that $\mathrm{AD}$ is a progressive disease and that disease modifying treatments should be tested as early as possible in the disease process to increase the likelihood of their success [5, 6]. The identification of early risk factors for $\mathrm{AD}$ will allow early identification of patients and thus increase the chance of a successful outcome of treatment strategies.

Dogs develop cerebral amyloid plaques with increasing age and are used as a natural model of age-dependent cognitive dysfunction [7-10]. There is a high level of homology between human and canine amyloid- $\beta$ protein precursor (A $\beta P P)$ isoforms and the proteases implicated in the amyloidogenic and non-amyloidogenic A $\beta P P$ processing pathways, as well as in the enzymes implicated in $A \beta$ degradation [11]. Consequently, the profile of $A \beta$ isoforms [12] and the turnover of $A \beta$ in the CSF of dogs are comparable to those seen in human CSF [13]. The association between brain and CSF $A \beta$ with aging in dogs is similar to that observed in AD patients, such that percent $A \beta_{42}$ in CSF decreases with increased plaque load in brain [9]. Impairment on specific cognitive domains is linked to brain-region specific amyloid load and cerebral atrophy measured by magnetic resonance imaging [14]. The pattern of age-dependent cognitive decline in dogs parallels that of $\mathrm{AD}$ with early impairments seen in shortterm working memory and executive function [15]. Collectively, the cross-sectional studies examining age-related differences in canine cognitive function, $\mathrm{A} \beta$ pathology, and in vivo $\mathrm{AD}$ imaging biomarkers support the use of the aging dog as a model of AD progression. However, longitudinal studies examining the temporal relationship between biomarkers and cognitive dysfunction are lacking, particularly in young subjects.

The current study sought to expand on the utility of the dog as a model of $\mathrm{AD}$ progression by examining the relation between CSF $A \beta_{42}$ level and cognitive function in young to middle-aged beagle dogs, being 1.5 to 7 years old. Specifically, dogs were selected from a larger colony from which $A \beta$ concentrations in CSF sampled from lateral ventricle were measured over a period of approximately two years. Since beagle dogs start to develop amyloid plaques from an age of 8 years onwards [9], it was assumed that amyloid deposition in the brain of these dogs would be minimal or absent. Thus, the rationale was to evaluate how differences in CSF $A \beta_{42}$ concentrations impacted cognitive performance in dogs unlikely to demonstrate cerebral amyloid deposition. Specifically, two groups of dogs, one with low and one with high CSF $\mathrm{A} \beta_{42}$ concentrations, were identified for further evaluation using standard laboratory cognition tests [16].

Additional analyses were done on CSF to characterize the dogs with different CSF $A \beta_{42}$ concentrations further. The measurements of $\operatorname{sA} \beta P P \alpha$ and $\mathrm{SA} \beta P P \beta$ provide an indication on the status of the $\alpha$ - and $\beta$-secretase A $\beta P P$-processing pathways. A panel of cytokines was measured, since the immune system may interact with $A \beta$-peptides.

\section{MATERIALS AND METHODS}

\section{Selection of animals}

Over a period of two years, $A \beta_{37}, A \beta_{38}, A 40$, and $\mathrm{A} \beta_{42}$ levels were measured at multiple time points in CSF from 73 beagle dogs ( 35 males and 38 females). CSF was sampled from the lateral ventricle in conscious animals [17]. The age of the animals varied from 1.5 to 7 years. From this group, ten animals with low mean $A \beta_{42}$ levels in CSF ( 6 males and 4 females) and ten animals with high mean $A \beta_{42}$ levels (4 males and 6 females) were selected (Fig. 1). These animals showed low $(<600 \mathrm{pg} / \mathrm{ml})$ or high $(>600 \mathrm{pg} / \mathrm{ml})$ $\mathrm{A} \beta_{42}$ concentrations in $>60 \%$ of the samples, with $600 \mathrm{pg} / \mathrm{ml}$ being approximately the median value of the whole population (Fig. 2). Only animals with at least three measurements were considered for inclusion. The $A \beta_{42}$ concentrations were consistent with the other $A \beta$ peptides measured, i.e., animals with low or high $A \beta_{42}$ levels also showed low or high concentrations of the other $A \beta$ peptides. The ratio of $A \beta_{42} / A \beta_{40}$ was comparable between the groups (Fig. 3). The mean age, $49 \pm 14$ months (min $27-$ max 72 months) and $49 \pm 19$ months (min $19-\max$ 73 months) and body weight, $9.4 \pm 1.1 \mathrm{~kg}(\min 7.5-$ $\max 10.6 \mathrm{~kg})$ and $9.1 \pm 1.1 \mathrm{~kg}(\min 6.8-\max 10.6 \mathrm{~kg})$ for the dogs in the low and high $\mathrm{A} \beta$-group, respectively, were also comparable (individual ages at time of sampling are shown in Supplementary Figure 1).

All studies were approved by the local animal ethical committee and all studies were conducted in facilities accredited by national institutions adhering to AAALAC guidelines.

\section{Multiplex immunoassay method for quantification of $A \beta_{37 / 38 / 40}$ and $A \beta_{42}$ levels in CSF}

Simultaneous specific quantification of humantype $A \beta_{37}, A \beta_{38}, A \beta_{40}$, and $A \beta_{42}$ in dog CSF was 


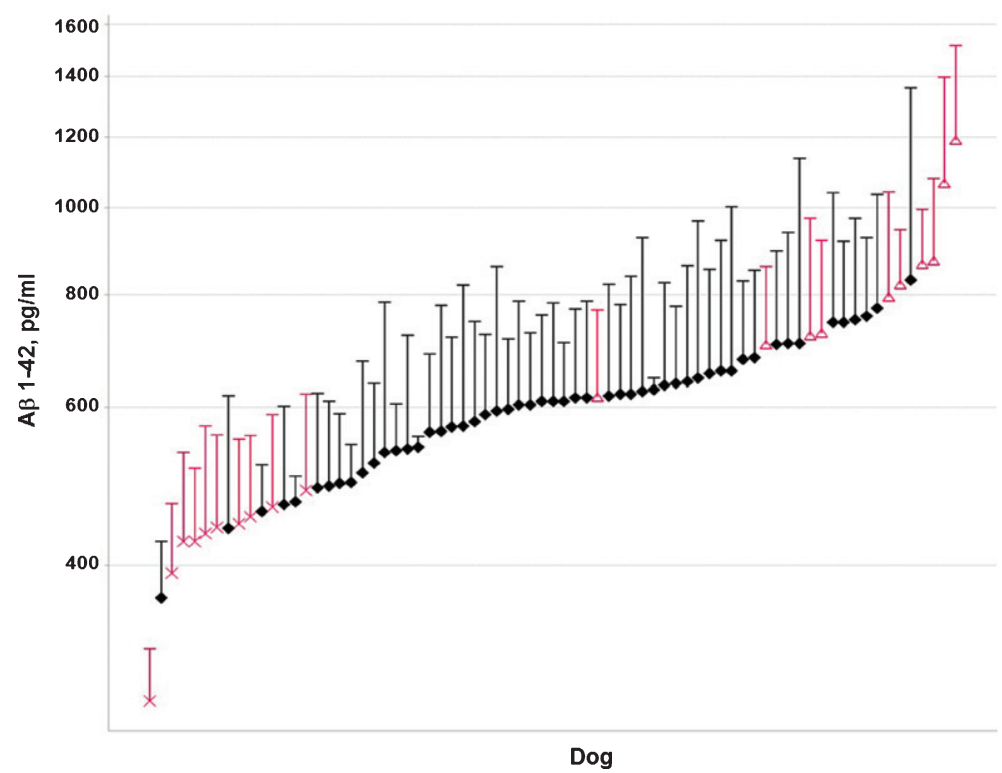

Fig. 1. Mean (+SD) $\mathrm{A} \beta_{42} \mathrm{CSF}$ concentrations (pg/ml) of individual animals over a period of two years in the larger colony of dogs $(n=73)$. Animals selected for the low and high $\mathrm{A} \beta_{42}$ subgroups are indicated in grey.

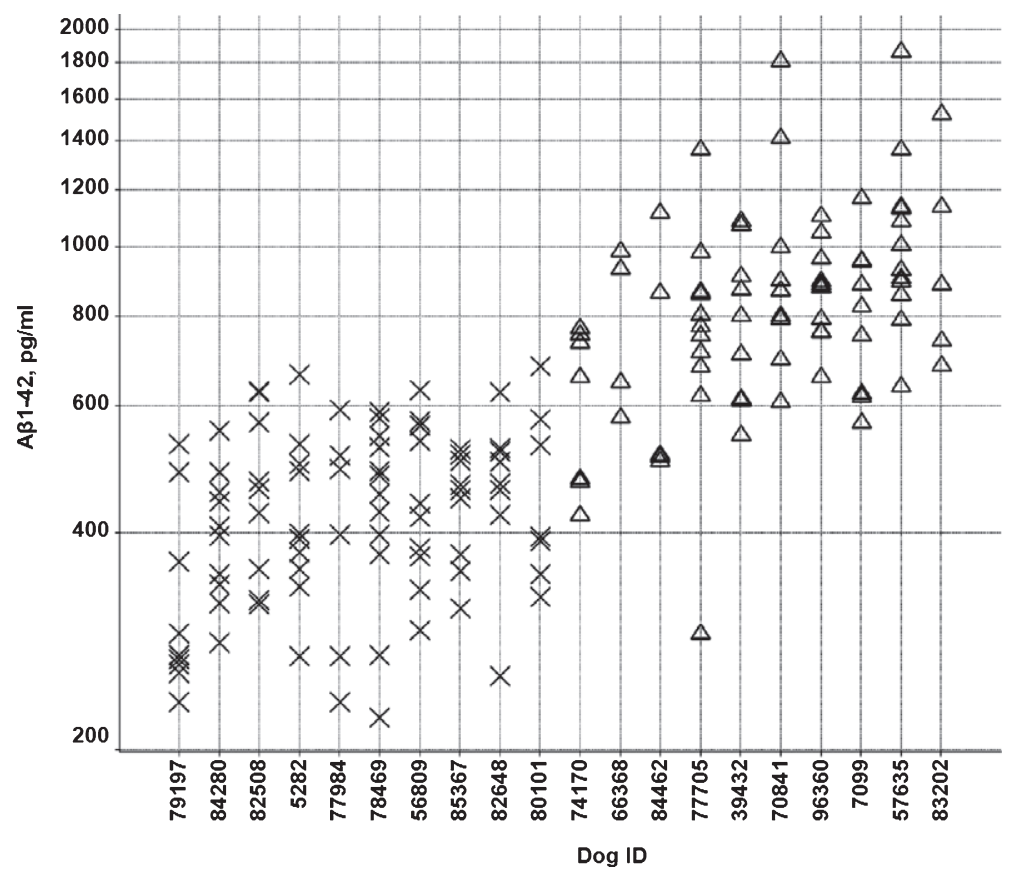

Fig. 2. Individual $A \beta_{42}$ CSF concentrations (pg/ml) over a period of two years in the low (X) and high ( $\Delta$ ) $A \beta$ groups.

performed using MesoScale Discovery (MSD, Gaithersburg, USA) electrochemiluminescence detection technology. Standards of human $A \beta_{37}$, $A \beta_{38}, A \beta_{40}$, and $A \beta_{42}$ (Anaspec, San Jose, CA) were dissolved in dimethylsulphoxide (DMSO) at
$0.1 \mathrm{mg} / \mathrm{ml}$ and stored at $-80^{\circ} \mathrm{C}$. For use in the assay, peptides were further diluted in casein buffer $(0.1 \%$ casein in PBS) to $10 \mathrm{pg} / \mathrm{ml}$. Purified monoclonal antibodies specific for $A \beta_{37}$ (JRD/A $\left.\beta 37 / 3\right), A \beta_{38}$ $(\mathrm{J} \& J P R D / A \beta 38 / 5), \quad A \beta_{40} \quad(\mathrm{JRF} / \mathrm{cA} \beta 40 / 28), \quad$ and 


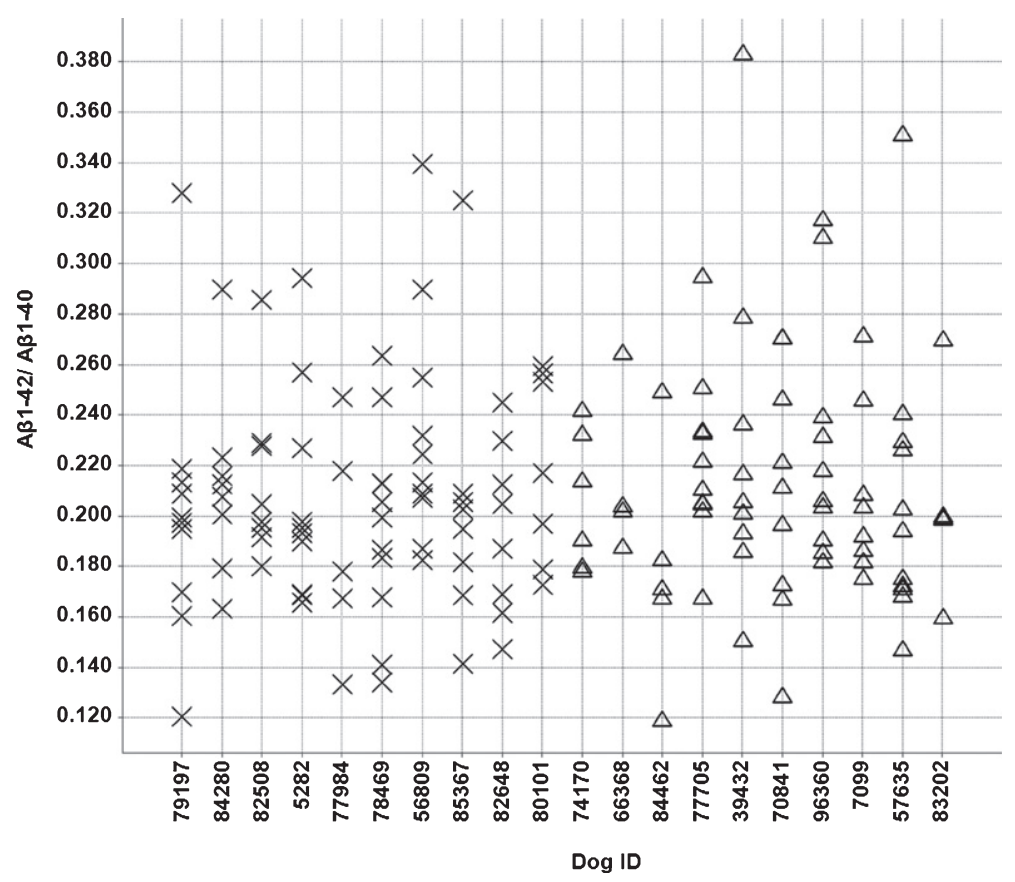

Fig. 3. Individual CSF $A \beta_{42} / A \beta_{40}$ ratios in the low (X) and high $(\Delta) A \beta$ groups.

$\mathrm{A} \beta_{42}(\mathrm{JRF} / \mathrm{A} \mathrm{A} \beta 42 / 26)$ were coated on MSD 4-plex 96-well plates. Plates were blocked with casein buffer $(0.1 \%$ casein in phosphate buffered saline (PBS) buffer) for $1-4 \mathrm{~h}$ at room temperature. After washing, standards and prediluted samples (1/2 dilution of the samples) were incubated in MSD 4-plex plates (Mesoscale Discovery) overnight at $4^{\circ} \mathrm{C}$ together with SULFO-TAG-labeled human-specific detection antibody JRF/A $\beta N / 25$. The SULFO-TAG emits light upon electrochemical stimulation initiated at the electrode surface of the 4-plex plates. After overnight incubation, plates were washed and assays were developed using 2x Read Buffer (Mesoscale Discovery) according to the manufacturer's recommendations and plates were read on MSD Sector Imager 6000. CSF samples contaminated with blood were not used in the analyses.

All calibration standards and study samples were analyzed in duplicate. The results were averaged and treated as a single value for all further calculations only if replicate CVs were less than or equal to $20.0 \%$. Any sample not meeting this criterion was excluded from any further calculation. The lowest limit of quantification, determined as the lowest calibrator concentration for which overall $\mathrm{CV}$ and bias were $\leq 25.0 \%$, was $4.57 \mathrm{pg} / \mathrm{ml}$ for all $\mathrm{A} \beta$-peptides measured.

\section{Immunoassay method for quantification of $s A \beta P P \alpha$ and $S A \beta P P \beta$ in $C S F$}

Specific quantification of $\mathrm{sA} \beta P P \alpha$ and $\mathrm{sA} \beta P P \beta$ in dog CSF was performed using MSD's electrochemiluminescence detection technology. $\mathrm{sA} \beta P P \alpha$ and $\mathrm{SA} \beta P P \beta$ standards were obtained in stock solution $(50.0 \mu \mathrm{g} / \mathrm{mL}$ of recombinant human $\mathrm{SA} \beta P P \alpha$ or sA $\beta P P \beta)$ as part of the MSD 96-Well MULTI-SPOT sA $\beta P P \alpha / \beta$ Assay kit ${ }^{\circledR}$ and further diluted in antibody dilution buffer to $0.411 \mathrm{ng} / \mathrm{ml}$. Purified monoclonal antibodies 6E10 (beta amyloid, 1-16; Covance) and JRD/sA $\beta P P / 23$ (in house) were coated on multi-array 96-well Plate SECTOR Standard MSD plates. Plates were blocked with casein buffer $(0.1 \%$ casein in PBS buffer) for $1 \mathrm{~h}$ at room temperature. After washing, standards and prediluted samples (1/8 for $\mathrm{sA} \beta \mathrm{PP} \alpha$ and $1 / 3$ for $\mathrm{s} A \beta P P \beta$ ) were incubated for $1 \mathrm{~h}$ at room temperature. After washing, SULFO-TAG-labeled detection antibodies, JRD/sA $\beta P P / 23$ for $\mathrm{sA} \beta P P \alpha$ or $\mathrm{J} \& \mathrm{~J} / \mathrm{PRD} / \mathrm{sA} \beta P P \beta / 2$ for $\mathrm{SA} \beta \mathrm{PP} \beta$ were incubated for $1 \mathrm{~h}$ at room temperature. Plates were washed and assays are developed using 1x Read Buffer $\mathrm{T}$ with surfactant (MSD) according to the manufacturer's recommendations and plates were read on MSD Sector Imager 6000. CSF samples contaminated with blood were not used in the analysis. 
All calibration standards and study samples were analyzed in duplicate. The results were averaged and treated as a single value for all further calculations only if replicate CVs were less than or equal to $20.0 \%$. Any sample not meeting this criterion was excluded from any further calculation. The lowest limit of quantification, determined as the lowest calibrator concentration for which overall $\mathrm{CV}$ and bias were $\leq 25.0 \%$, was $1 \mathrm{ng} / \mathrm{ml}$ for both sA $\beta P P s$ measured.

\section{Multiplex immunoassay method for quantification of cytokines}

CSF samples were stored at $-80^{\circ} \mathrm{C}$ until analysis and all measurements were performed on a Magpix multiplex immunoassay instrument (Luminex), using xPonent 4.2 and BioPlex Manager 6.2 (Bio-Rad) for data analysis. The Milliplex MAP Canine Cytokine/Chemokine Magnetic Bead Panel (CCYTOMAG-90K, Millipore) was used according to the kit insert to determine GM-CSF, IFN $\gamma$, IL-2, IL-6, IL-7, IL-8, IL-10, IL-15, IL-18, IP10, KC-like (CXCL-1), MCP-1, and TNF $\alpha$ levels in all CSF samples described above.

\section{Cognition testing}

\section{Apparatus and general procedures}

All cognitive testing was conducted in a standardized test apparatus and employed food-reward based procedures as described previously [18]. Specifically, for each cognitive test, the dog entered a chamber separated from the tester and test preparation area by an opaque barrier. The barrier prevented the dog from seeing the tester or test preparation procedures, but allowed the tester to observe the dog through a oneway glass. The tester prepared the three-well test tray between test trials by placing a food reward in the correct well and by placing appropriate objects on the tray such that the correct object, as applicable, was placed over the food reward. During a test trial, the tester presented the objects to the dog on a sliding tray (Fig. 4), and after an inspection interval, allowed the dog to select and move an object with its snout. If the dog selected the correct object or location, the food reward was uncovered and could be consumed by the dog. A correction procedure was used in which a dog was permitted to correct their response only after the first incorrect response within a daily test session.

All dogs underwent a standardized pre-training procedure described previously [18], which included acclimation, reward approach learning, and object

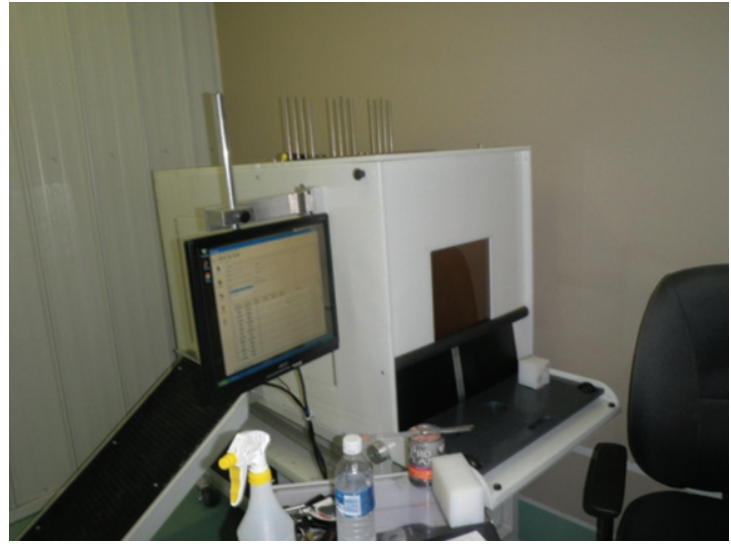

Fig. 4. The cognitive test apparatus used for canine cognitive testing. The dog enters the test chamber via the ramp and is separated from the experimenter by an opaque barrier with a one-way mirror. The computer prompts the experimenter with respect to correct location of the test objects and records responses by key press.

approach learning before being tested on object discrimination and reversal learning followed by delayed non-matching to position task (DNMP) learning. A dedicated computer program (VariCog, CanCog Technologies Inc., Toronto, Canada) that controlled location randomization across trials and sessions and that allowed testers to record subject responses by key-press was used for all tasks described below.

\section{Reward and object approach learning (procedural learning)}

Reward and object approach learning are procedural learning tasks used to shape subject responses for subsequent cognitive tests. During reward approach learning, dogs were required to locate in which of three wells a food reward was placed and to consume it before proceeding to subsequent trials. During object approach learning, dogs were required to move an object placed over one of the three wells so that the food reward beneath could be retrieved. Dogs were required to achieve a minimum of $16 / 21$ correct responses on a single day or $9 / 10$ correct responses on 10 consecutive trials, before proceeding to the next phase of pre-training. Cumulative errors to pass each task were used to evaluate group differences.

\section{Object discrimination and reversal learning}

Prior to object discrimination learning, a preference test was conducted for each dog in which two objects were randomly placed over the two lateral food wells each containing a food reward. The object 
selected most frequently over 10 trials was considered the preferred object. For object discrimination learning, dogs were presented with both objects over 20 trials during each daily session and the food reward was always located in the well underneath the preferred object. Once the learning criteria was achieved, dogs were tested on the object discrimination reversal task, which was identical to the object discrimination learning task except that the non-preferred object always covered the well with the food reward. The learning criteria for both tasks consisted of two stages. The first stage required dogs to respond correctly on a minimum of $18 / 20$ correct trials on a single day or a minimum of $16 / 20(80 \%)$ trials over two consecutive days. The second stage required dogs to respond correctly on a minimum of $28 / 40(70 \%)$ trials over the subsequent two consecutive days. Errors to pass were used to evaluate group and task differences.

\section{DNMP}

The DNMP has been described previously $[8,19]$. Briefly, each trial of the DNMP consisted of a sample, delay, and choice phase. During the sample phase, an object was presented over a food reward placed in one of the three positions on the food tray. After the dog obtained the food reward, the 5-s delay period was initiated immediately after the tray was removed from the dog's sight. During the delay phase, the tester prepared the tray for presentation during the choice phase. After the delay, the choice phase was initiated in which the dog was presented with two objects, which were identical to that used in the sample phase, but one was located over the sample position and the other covered a food reward in one of the remaining two (non-match) position. The correct response was to select the object in the non-match position (Fig. 5). There were 12 trials per daily session and the learning criteria consisted of two stages. For the first criterion stage, a minimum of 11/12 (90\%) correct responses on a single day, 10/12 (80\%) correct responses over two consecutive days, or 29/36 (80\%) correct responses over three consecutive days were required. The second criterion stage required dogs to perform above $70 \%$ accuracy over the subsequent three days.

\section{Statistics}

A hierarchical model was fit to the $\mathrm{sA} \beta P P \beta$, sA $\beta P P \alpha$, and cytokine data with the $A \beta$ group (high or low $A \beta_{42}$ levels) and period as fixed effect and a random intercept to account for the nested structure of

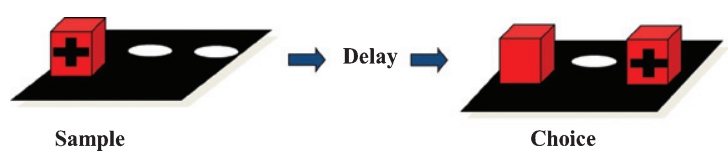

Fig. 5. Delayed non match to position (DNMP): This task consisted of a sample presentation, a delay (starting with $5 \mathrm{sec}$ ) and a choice presentation. Choice of the non-sample position resulted in a food reward (indicated by the "+" sign).

the data, i.e., the replicated samples within the same animal.

Differences between $\mathrm{A} \beta$ groups on cognitive tests were evaluated by comparing mean cumulative errors to pass tasks. $A \beta$ group comparisons were conducted using analysis of variance (ANOVA). For the object discrimination and reversal learning task a repeatedmeasures three-way ANOVA was used with task (discrimination and reversal) serving as a withinsubject variable and with $A \beta$ group (low and high $\mathrm{A} \beta{ }_{42}$ concentration $)$ and age $(<5$ year $=$ young versus $>5$ year $=$ old $)$ serving as between-subject variables. For the other tasks, a two-way ANOVA was used with $A \beta$ group (low and high $A \beta_{42}$ concentration) and age (young versus old) serving as between-subject variables. Fisher's post-hoc test was used to evaluate task, age and group differences as appropriate. Additionally, analyses examining correlations between CSF $A \beta_{42}$ levels and errors conducted on cognitive tests for each $A \beta_{42}$ group, as well as for all subjects collectively. The cognitive test analyses were conducted using the Statistica 11.0 (StatSoft, Tulsa, OK, USA) software package with significance set to $p<0.05$.

\section{RESULTS}

\section{$s A \beta P P \alpha, s A \beta P P \beta$, and cytokines}

sA $\beta P P \alpha, s A \beta P P \beta$, and cytokines were measured in eight animals of each group. Lower and higher sA $\beta P P \alpha$ and $\mathrm{sA} \beta P P \beta$ concentrations in CSF were measured in the low and high $A \beta$ groups, respectively (Fig. 6). The high $A \beta$ group had an average of $48 \mathrm{ng} / \mathrm{ml} \mathrm{sA} \beta \mathrm{PP} \alpha$ in CSF, whereas the the low group had an average of $29 \mathrm{ng} / \mathrm{ml}(p=0.0001)$. For $\mathrm{sA} \beta P P \beta$, the average values were 68 and $41 \mathrm{ng} / \mathrm{ml}$ in the high and low $\mathrm{A} \beta$ groups, respectively $(p<0.0001)$. Only the cytokines IL-8, KC-like (CXCL-1) and MCP1 could be measured, all other analytes (GM-CSF, IFN $\gamma$, IP10, IL-2, IL-6, IL-7, IL-10, IL-15, IL-18 and $\mathrm{TNF} \alpha$ ) were below or only slightly above the lower limit of quantification. 

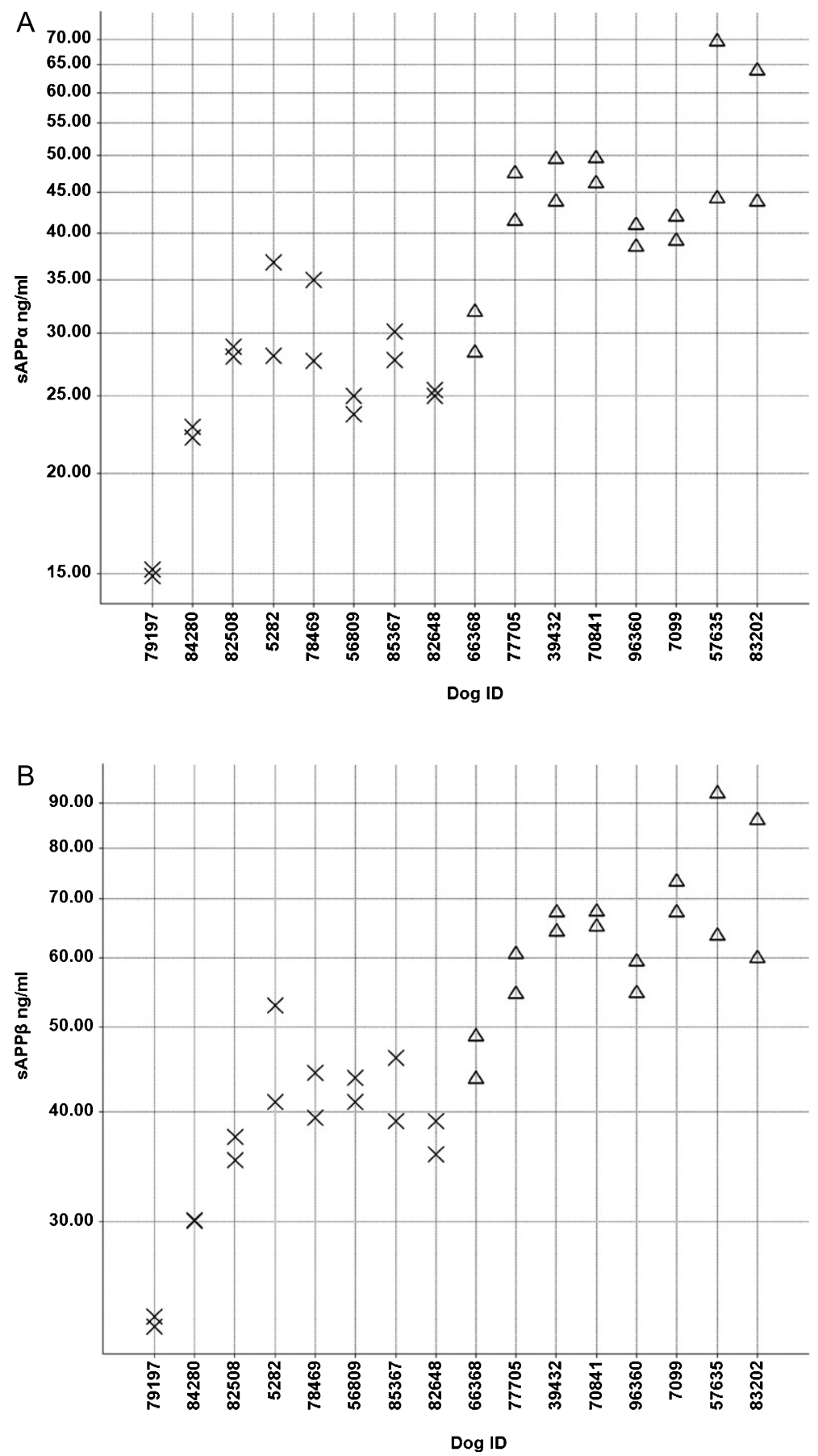

Fig. 6. Individual sA $\beta P P \alpha(\mathrm{A})$ and $\mathrm{sA} \beta \mathrm{PP} \beta$ (B) CSF concentrations (ng/ml) in the low (X) and high ( $\Delta) \mathrm{A} \beta$ groups.

IL-8 and MCP-1 concentrations were comparable between both groups (data not shown). CXCL-1 was higher in the high $\mathrm{A} \beta$ group compared to the low $\mathrm{A} \beta$ group (Fig. 7). Average values were 140 and $95 \mathrm{pg} / \mathrm{ml}$ in the high and low $\mathrm{A} \beta$ group, respectively $(p=0.0215)$.

\section{Cognition tests}

Two dogs in the high $\mathrm{A} \beta$ group did not complete the cognitive phase of the study. One animal died as a consequence of congestive heart failure during the object discrimination task, therefore this dog's data 


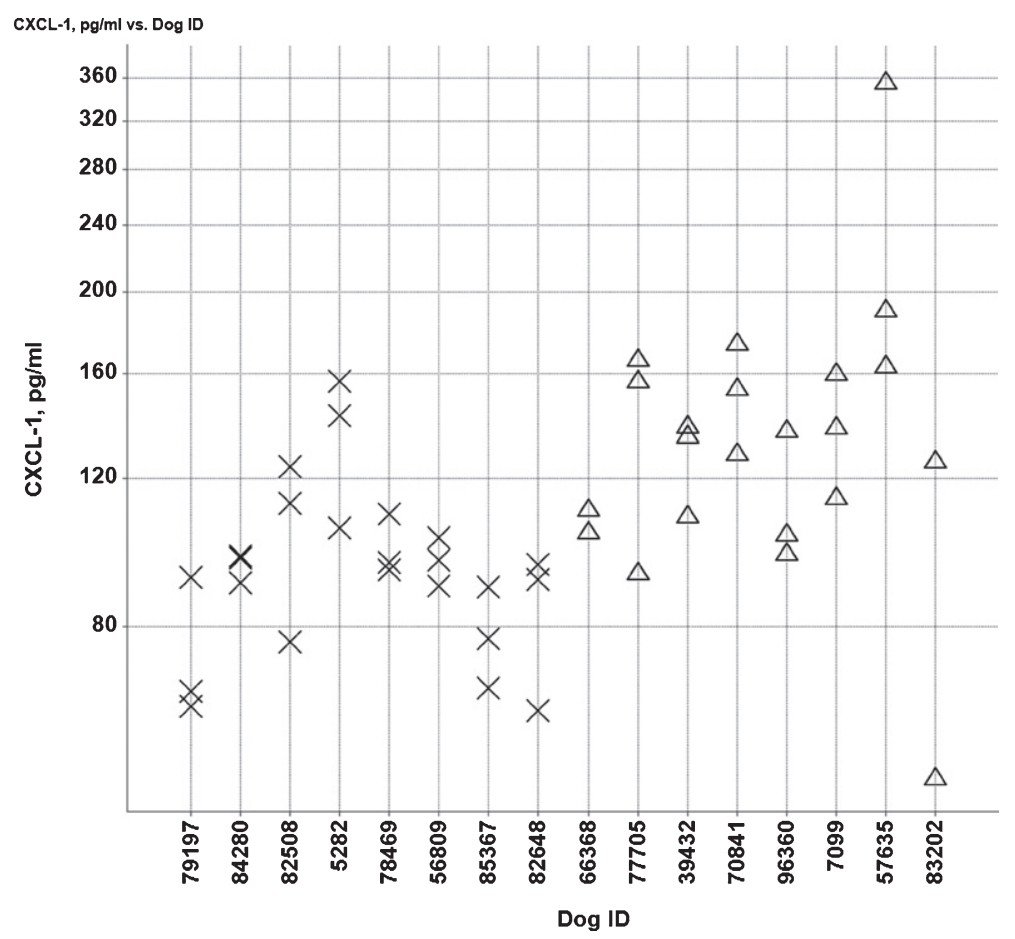

Fig. 7. Individual CXCL-1 CSF concentrations (pg/ml) in the low $(\mathrm{X})$ and high $(\Delta) \mathrm{A} \beta$ groups.

were excluded from the object discrimination and reversal learning analysis. One dog was euthanized due to uncontrollable seizures during discrimination reversal learning and therefore errors to pass this task were not included in the object discrimination and reversal learning analysis. Both mortalities were considered coincidental and unrelated to the experiment or their CSF amyloid status. Thus, at least two dogs in the young $(<5 \mathrm{y})$ low $A \beta$ group, seven in the old $(>5 \mathrm{y})$ low $A \beta$ group, three in the young high $A \beta$ group, and four in the old high $A \beta$ group were included in the analyses.

\section{Reward and object approach}

All dogs passed both tests and there were no statistically significant group differences on either task (Fig. 8) nor was CSF A $\beta_{42}$ level correlated with performance on either task.

\section{Discrimination and reversal learning}

All dogs in the low $A \beta$ group passed discrimination and reversal learning. In the high $A \beta$ group, nine out of nine animals passed discrimination learning and eight out of eight passed reversal learning. The ANOVA revealed significant effects of both task $(\mathrm{F}(1,14)=18.30 ; p<0.001)$ and $\mathrm{A} \beta$ group $(\mathrm{F}(1,14)=7.21 ; p<0.05)$. Mean cumulative errors were significantly higher during reversal learning regardless of group, and the high $\mathrm{A} \beta$ group showed significantly more errors overall (Fig. 9). No main age effects or interactions were found, although errors on the discrimination learning $(\mathrm{r}(16)=0.54$, $p<0.05)$ and reversal learning $(\mathrm{r}(16)=0.49, p<0.05)$ tasks were correlated significantly and positively with CSF $A \beta_{42}$ levels when all subjects were considered (Fig. 9).

\section{Delayed non-match to position (DNMP)}

All dogs, but one, that passed object discrimination reversal learning also passed the 5-s DNMP such that 10 subjects in the low $A \beta$ group and 7 subjects in the high $A \beta$ group passed. One subject in the low $A \beta$ group proved to be an outlier substantially exceeding 2.5 standard deviations of the population mean and therefore was excluded from the statistical analysis. The resultant analysis indicated significantly $(\mathrm{F}(1,12)=10.19 ; p<0.01)$ higher cumulative errors to learn the DNMP at $5 \mathrm{~s}$ in the high $\mathrm{A} \beta$ group compared to the low $A \beta$ group (Fig. 10). A significant main effect of age group $(\mathrm{F}(1,12)=7.18 ; p<0.05)$ and a marginally significant interaction between $A \beta$ 
A

$$
\text { ڤ. }
$$

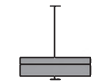

High RAO
High RAY

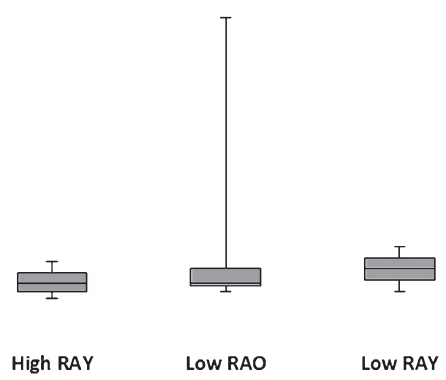

Reward Approach

Object Approach
A

300

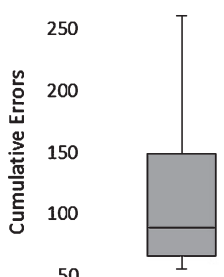

0

High DLO

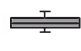

High DLY

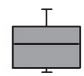

Low DLO

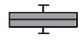

Low DLY

Discrimination Reversal

B

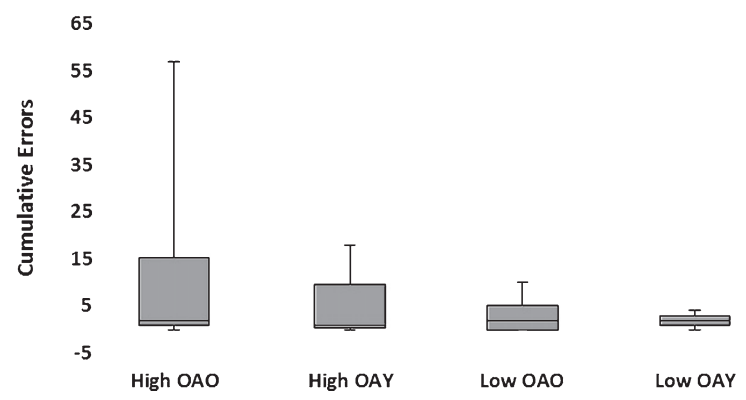

Fig. 8. Box plots of cumulative errors committed per $A \beta$ and age group to learn the reward (A) and object approach (B) tasks. High and low $A \beta$ groups are indicated by $\mathrm{H}$ and $\mathrm{L}$, respectively. Old $(>5 \mathrm{y})$ and young $(<5 \mathrm{y})$ are indicated by $\mathrm{O}$ and $\mathrm{Y}$, respectively.

group and age $(\mathrm{F}(1,12)=3.84 ; p=0.073)$ was found with aged dogs performing more poorly than young. The interaction reflected a significant impairment in aged dogs with high $A \beta$ (Fig. 10). Moreover, errors on the DNMP learning were correlated significantly $(\mathrm{r}(14)=0.55, p<0.05)$ and positively with $\mathrm{CSF} \mathrm{A} \beta_{42}$ levels when all subjects were considered (Fig. 10).

\section{DISCUSSION}

CSF A $\beta_{42}$ concentration has proven to be a reliable biomarker for predicting conversion to $\mathrm{AD}$ and the decrease in CSF $A \beta_{42}$ reflects brain amyloid deposition [20]. Nearly all data examining CSF $A \beta_{42}$, as a biomarker for $\mathrm{AD}$ progression are from humans older than 40-50 years and reflect age-matched healthy controls for comparison to AD patients. Data in younger populations, before amyloid deposition is expected, are scarce. In young adults with autosomal dominant familial $\mathrm{AD}$ genetics, an overproduction of $\mathrm{A} \beta$, resulting in increased CSF $A \beta$ levels, is shown 25 years prior onset to AD symptoms [21, 22].

B

700

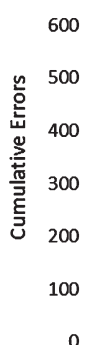

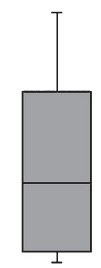

High DRO
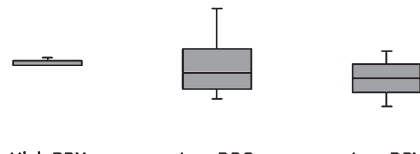

High DRY

Low DRO

Low DRY

Fig. 9. Box plots of cumulative errors committed per $A \beta$ and age group to pass the discrimination (A) and reversal learning (B) tasks. High and low $\mathrm{A} \beta$ groups are indicated by $\mathrm{H}$ and $\mathrm{L}$, respectively. Old ( $>5 \mathrm{y})$ and young $(<5 \mathrm{y})$ are indicated by $\mathrm{O}$ and $\mathrm{Y}$, respectively.

\section{5s DNMP}

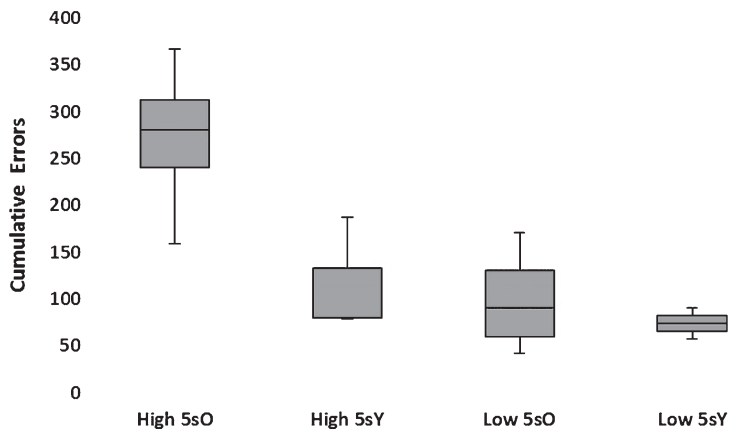

Fig. 10. Box plots of cumulative errors committed per $A \beta$ and age group to pass the 5-s DNMP. High and low $A \beta$ groups are indicated by $\mathrm{H}$ and $\mathrm{L}$, respectively. Old $(>5 \mathrm{y})$ and young $(<5 \mathrm{y})$ are indicated by $\mathrm{O}$ and $\mathrm{Y}$, respectively.

In canine aging, amyloid deposition, which coincides with a decrease in CSF $A \beta_{42}$, is seen in dogs from approximately 8 years onwards [9]. In the current study, the dogs were 1.5-7 years old and therefore unlikely to have significant age-related cerebral amyloid deposition. Thus, the dogs in the current study 
likely correspond to humans ranging from young adult to middle age. Although quantification of $A \beta_{42}$ on different plates precludes comparisons of absolute values, the dogs included in the current study had consistently low or high concentrations of CSF $\mathrm{A} \beta_{42}$ than the population mean, which was approximately $600 \mathrm{pg} / \mathrm{ml}$ of $A \beta_{42}$ in CSF. We have shown previously that $A \beta$ concentrations differ from one compartment to another [23], and thus the absolute values of CSF $A \beta_{42}$ in the current study can only be compared with concentrations in CSF obtained under the same conditions. $\mathrm{sA} \beta P P \beta$ as well as $\mathrm{sA} \beta P P \alpha$ were higher in the high $A \beta$ group, indicating that the difference in $A \beta$ concentrations between the groups might be related to an increase in expression level and/or overall processing of $A \beta P P$.

Sources of the chemokine CXCL-1, a ligand of CXCR2, in the brain include microglia, astrocytes, endothelial cells and infiltrated neutrophils [24]. It is a cytokine which is basally secreted by non-stimulated astrocytes [25]. Quiescent microglia are very active in maintaining brain homeostasis and show high mobility and cytokines secretion [26, 27]. It is also known that microglia can be activated by $\mathrm{A} \beta$ oligomers [28, $29]$ and that the formation of $A \beta$ oligomers appears to be dependent on the levels of $A \beta$ production [30]. Therefore, although $A \beta$ oligomers were not measured in the current study, a higher concentration of $A \beta$ oligomers is hypothesized in dogs with higher $A \beta$ levels, which could lead to increased activation of microglia and consequently increased production of CXCL-1.

Object discrimination and reversal learning, as well as DNMP learning, are standard age-sensitive cognition tests used to evaluate and compare cognitive performance among laboratory dogs. At the onset of the study, the goal was to follow changes in cognitive performance in both $\mathrm{A} \beta$ groups as the dogs aged, however a difference in learning ability between both groups was found at this relatively young age. The learning impairments reported here were unlikely related to brain amyloid deposition. A more likely explanation is that increased $A \beta$ processing resulted in increased levels of $A \beta$ and possibly increased levels of amyloid oligomers contributed to the learning impairments reported here [31]; however, other mechanisms linked to a higher CSF A $\beta$ concentration cannot be ruled out. Interestingly, the finding that old dogs with high CSF levels of $A \beta$ were significantly impaired compared to young dogs in the same amyloid group on the DNMP, but not object discrimination and reversal learning is consistent with previous findings indicating DNMP learning is impaired early in canine aging [15].

Although the differences in learning ability between the $A \beta$ groups were statistically significant, confirmation of these results in additional animals is warranted. An important obstacle in performing confirmatory studies is the difficulty in identifying dogs with consistent low and high CSF A $\beta$ levels. A sufficiently long screening period in a large population is required to confidently select individual dogs based on CSF A $\beta$ levels. Nevertheless, the current finding suggests that high $A \beta_{42}$ early in life may be linked to learning impairments in dogs. The translational value of this observation is yet to be determined, therefore follow-up studies in these and other dogs may provide further insight on the impact of CSF A $\beta_{42}$ levels on cognitive status and may contribute to the identification of early biomarkers of risk factors that predict the trajectory of $\mathrm{AD}$ progression.

\section{CONCLUSION}

In the current study, dogs with high CSF $\mathrm{A} \beta_{42}$ levels, at an age where no deposition of amyloid in brain was expected, demonstrated learning impairments on standard cognition tests. The data suggest that high levels of $A \beta_{42}$, possibly due to increased $\mathrm{A} \beta$-peptide production and/or the anticipated subsequent increase in amyloid oligomers are predictive of significant learning impairments. The translational value of these findings is yet to be determined. However, since these learning impairments likely precede cerebral amyloid deposition, this finding suggests that high CSF $A \beta_{42}$ may serve as an early biomarker for AD-like cognitive impairment, which can present early in disease progression. Therefore, CSF $\mathrm{A} \beta_{42}$ screening of young people with a family history of $\mathrm{AD}$ or with learning disabilities is recommended. If these findings are confirmed, available $A \beta$ lowering therapies should be evaluated for treatment and/or prevention of learning deficits in this patient population.

\section{ACKNOWLEDGMENTS}

The authors wish to thank Dirk Smets, Rob Mostmans, Annik Vanlommel, Sigrid Janssens, and Greet Meulders for their technical support.

Authors' disclosures available online (http://j-alz. com/manuscript-disclosures/16-0434r2). 


\section{SUPPLEMENTARY MATERIAL}

The supplementary material is available in the electronic version of this article: http://dx.doi.org/ 10.3233/JAD-160434.

\section{REFERENCES}

[1] Nelson PT, Braak H, Markesbery WR (2009) Neuropathology and cognitive impairment in Alzheimer disease: A complex but coherent relationship. J Neuropathol Exp Neurol 68, 1-14.

[2] Bitan G, Kirkitadze MD, Lomakin A, Vollers SS, Benedek GB, Teplow DB (2003) Amyloid beta-protein (A $\beta$ ) assembly: $\mathrm{A} \beta 40$ and $\mathrm{A} \beta 42$ oligomerize through distinct pathways. Proc Natl Acad Sci U S A 100, 330-335.

[3] Cole SL, Vassar R (2008) The role of amyloid precursor protein processing by BACE1, the $\beta$-secretase, in Alzheimer disease pathophysiology. J Biol Chem 283, 29621-29625.

[4] Karran E, Mercken M, De Strooper B (2011) The amyloid cascade hypothesis for Alzheimer's disease: An appraisal for the development of therapeuticss. Nat Rev Drug Discov 10, 698-712.

[5] Sperling R, Aisen P, Beckett L, Bennet D, Craft S, Fagan A, Iwatsubo T, Jack C, Kaye J, Montine T, Park D, Reiman E, Rowe C, Siemers E, Stern Y, Yaffe K, Carrillo M, Thies B, Morrison-Bogorad M, Wagster M, Phelps C (2011) Toward defining the preclinical stages of Alzheimer's disease: Recommendations from the National Institute on Aging-Alzheimer's Association workgroups on diagnostic guidelines for Alzheimer's disease. Alzheimers Dement 7, 280-292.

[6] Waite LM (2015) Treatment for Alzheimer's disease: Has anything changed?. Aust Prescr 38, 60-63.

[7] Cotman CW, Head E (2008) The canine (dog) model of human aging and disease: Dietary, environmental and immunotherapy approaches. J Alzheimers Dis 15, 685-707.

[8] Studzinski CM, Araujo JA, Milgram NW (2005) The canine model of human cognitive aging and dementia: Pharmacological validity of the model for assessment of human cognitive-enhancing drugs. Prog Neuropsychopharmacol Biol Psychiatry 29, 489-498.

[9] Head E, Pop V, Sarsoza F, Kayed R, Beckett TL, Studzinski CM, Tomi JL, Glabe CG, Murphy MP (2010) Amyloid $\beta$ peptide and oligomers in the brain and CSF of aged canines. $J$ Alzheimers Dis 20, 637-646.

[10] Schmidt F, Boltze J, Jäger C, Hofmann S, Willems N, Seeger J, Härtig W, Stolzing A (2015) Detection and quantification of $\beta$-amyloid, pyroglutamyl $A \beta$ and tau in aged canines. J Neuropathol Exp Neurol 74, 912-923.

[11] Sarasa L, Gallego C, Monleon I, Olvera A, Canudas J, Montanes M, Pesini P, Sarasa M (2010) Cloning, sequencing and expression in the dog of the main amyloid precursor protein isoforms and some of the enzymes related with their processing. Neuroscience 171, 1091-1101.

[12] Portelius E, Van Broeck B, Andreasson U, Gustavsson MK, Mercken M, Zetterberg H, Borghys H, Blennow K (2010) Acute effect on the $A \beta$ isoform pattern in CSF in response to (-secretase modulator and inhibitor treatment in dogs. J Alzheimers Dis 21, 1005-1012.

[13] Lu Y, Barton HA, Leung L, Zhang L, Hajos-Korcsok E, Nolan CE, Liu J, Becker SL, Wood KM, Robshaw AE, Taylor CK, O’Neill BT, Brodney MA, Riddel D (2013)
Cerebrospinal fluid $\beta$-amyloid turnover in the mouse, dog, monkey and human evaluated by systematic quantitative analyses. Neurodegener Dis 12, 36-50.

[14] Tapp PD, Siwak CT, Gao FQ, Chiou JY, Black SE, Head E, Muggenburg BA, Cotman CW, Milgram NW, Su MY (2004) Frontal lobe volume, function and beta-amyloid pathology in a caning model of aging. J Neurosci 24, 8205-8213.

[15] Studzinski CM, Christie LA, Araujo JA, McIntyre Burnham W, Head E, Cotman CW, Milgram NW (2006) Visuospatial function in the beagle dog: An early marker of cognitive decline in a model of human aging and dementia. Neurobiol Learn Mem 86, 197-204.

[16] Adams B, Chan A, Callahan H, Milgram NW (2000) The canine as a model of human cognitive aging: Recent developments. Pro Neuropsychopharmacol Biol Psychiatry 24, 675-692.

[17] Wilsson-Rahmberg M, Olovson SG, Forshult E (1998) Method for long-term cerebrospinal fluid collection in the conscious dog. J Invest Surg 11, 207-214.

[18] Milgram NW, Head E, Weiner E, Thomas S (1994) Cognitive functions and aging in the dog: Acquisition of nonspatial visual tasks. Behav Neurosci 108, 57-68.

[19] Adams B, Chan A, Callahan H, Siwak C, Tapp D, IkedaDouglas C, Atkinson P, Head E, Cotman C, Milgram N (2000) Use of a delayed non-matching to position task to model age-dependent cognitive decline in the dog. Behav Brain Res 108, 47-56.

[20] Palmqvist S, Zetterberg H, Mattsson N, Johansson P (2015) Detailed comparison of amyloid PET and CSF biomarkers for identifying early Alzheimer disease. Neurology 85, 1240-1249.

[21] Reiman E, Quiroz Y, Fleisher A, Chen K, Velez-Pardo C, Jimenez-Del-Rio M, Fagan A, Shah A, Alvarez S, Arbelaez A, Giraldo M, Acosta-Baena N, Sperling R, Dickerson B, Stern C, Tirado V, Munoz C, Reiman R, Huentelman M, Alexander G, Langbaum J, Kosik K, Tariot P, Lopera F (2012) Brain imaging and fluid biomarker analysis in young adults at genetic risk for autosomal dominant Alzheimer's disease in the presenilin 1 E280A kindred: A case-control study. Lancet Neurol 11, 1048-1056.

[22] Bateman RJ, Xiong C, Benzinger TL, Fagan AM, Goate A, Fox NC, Marcus DS, Cairns NJ, Xie X, Blazey TM, Holtzman DM, Santacruz A, Buckles V, Oliver A, Moulder K, Aisen PS, Ghetti B, Klunk WE, McDade E, Martins RN, Masters CL, Mayeux R, Ringman JM, Rossor MN, Schofield PR, Sperling RA, Salloway S, Morris JC, Dominantly Inherited Alzheimer Network (2012) Clinical and biomarker changes in dominantly inherited Alzheimer's disease. $N$ Engl J Med 367, 795-804.

[23] Borghys H, Jacobs T, Van Broeck B, Dillen L, Dhuyvetter D, Gijsen H, Mercken M (2014) Comparison of two different methods for measurement of amyloid- $\beta$ peptides in cerebrospinal fluid after BACE1 inhibition in a dog model. $J$ Alzheimers Dis 38, 39-48.

[24] Semple BD, Kossmann T, Morganti-Kossmann MC (2010) Role of chemokines in CNS health and pathology: A focus on the CCL2/CCR2 and CXCL8/CXCR2 networks. J Cereb Blood Flow Metab 30, 459-473.

[25] Choi SS, Lee HJ, Lim I, Satoh JI, Kim SU (2014) Human astrocytes: Secretome profiles of cytokines and chemokines. PLoS One 9, e92325.

[26] Morris GP, Clark IA, Zinn R, Vissel B (2013) Microglia: A new frontier for synaptic plasticity, learning and memory and neurodegenerative disease research. Neurob Learning Mem 105, 40-53. 
[27] Cherry JD, Olschowka JA, O'Banion MK (2014) Neuroinflammation and M2 microglia: The good, the bad and the inflamed. J Neuroinflammation 11, 98.

[28] Guillot-Sestier MV, Town T (2013) Innate immunity in Alzheimer's disease: A complex affair. CNS Neurol Disord Drug Targets 12, 593-607.

[29] Liu S, Liu Y, Hao W, Wolf L, Kiliaan AJ, Penke B, Rübe CE, Walter J, Heneka MT, Hartmann T, Menger MD, Fassbender K (2012) TLR2 is a primary receptor for Alzheimer's amyloid $\beta$ peptide to trigger neuroinflammatory activation. J Immunol 188, 1098-1107.

[30] Larson ME, Lesné SE (2012) Soluble A $\beta$ oligomer production and toxicity. J Neurochem 120, 125-139.

[31] Pearson-Leary J, McNay E (2012) Intrahippocampal administration of Amyloid- $\beta 1-42$ oligomers acutely impairs spatial working memory, insulin signaling and hippocampal metabolism. J Alzheimers Dis 30, 413-422. 